\title{
A genome-wide association study using international breeding-evaluation data identifies major loci affecting production traits and stature in the Brown Swiss cattle breed
}

Jiazhong Guo ${ }^{1,2}$, Hossein Jorjani ${ }^{3}$ and Örjan Carlborg ${ }^{2^{*}}$

\begin{abstract}
Background: The genome-wide association study (GWAS) is a useful approach to identify genes affecting economically important traits in dairy cattle. Here, we report the results from a GWAS based on high-density SNP genotype data and estimated breeding values for nine production, fertility, body conformation, udder health and workability traits in the Brown Swiss cattle population that is part of the international genomic evaluation program.

Result: GWASs were performed using 50 k SNP chip data and deregressed estimated breeding values (DEBVs) for nine traits from between 2061 and 5043 bulls that were part of the international genomic evaluation program coordinated by Interbull Center. The nine traits were milk yield (MY), fat yield (FY), protein yield (PY), lactating cow's ability to recycle after calving (CRC), angularity (ANG), body depth (BDE), stature (STA), milk somatic cell score (SCS) and milk speed (MSP). Analyses were performed using a linear mixed model correcting for population confounding. A total of 74 SNPs were detected to be genome-wide significantly associated with one or several of the nine analyzed traits. The strongest signal was identified on chromosome 25 for milk production traits, stature and body depth. Other signals were on chromosome 11 for angularity, chromosome 24 for somatic cell score, and chromosome 6 for milking speed. Some signals overlapped with earlier reported QTL for similar traits in other cattle populations and were located close to interesting candidate genes worthy of further investigations.
\end{abstract}

Conclusions: Our study shows that international genetic evaluation data is a useful resource for identifying genetic factors influencing complex traits in livestock. Several genome wide significant association signals could be identified in the Brown Swiss population, including a major signal on BTA25. Our findings report several associations and plausible candidate genes that deserve further exploration in other populations and molecular dissection to explore the potential economic impact and the genetic mechanisms underlying these production traits in cattle.

\section{Background}

Genome wide association studies (GWAS) have for a number of years been a useful tool for detecting genetic variants associated with complex traits in human genetics $[1,2]$. With the advancement of genotyping and sequencing technology, platforms for high-density genotyping have been developed for other species as well a development that has facilitated GWAS also in e.g.

\footnotetext{
* Correspondence: Orjan.Carlborg@slu.se

${ }^{2}$ Department of Clinical Sciences, Division of Computational Genetics,

Swedish University of Agricultural Sciences, Uppsala, Sweden

Full list of author information is available at the end of the article
}

livestock [3-7], domesticated plants [8] and model organisms [9].

Since the seminal QTL mapping work in cattle by Georges et al. [10], a large number of studies have reported QTL for many different traits in various breeds. The limitation of QTL mapping in identifying the causal variants underlying the studied traits using the low to moderate dense marker maps have been discussed in depth elsewhere $[11,12]$. In contrast to traditional QTL mapping strategies, GWAS opens new opportunities to make efficient use of outbred cattle populations for high-resolution mapping of loci of even modest

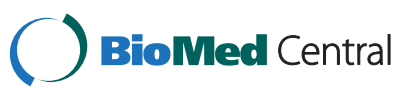


effects underlying important production traits [13]. A main motivation for performing GWASs in domesticated animals, like dairy cattle, is thus to discover genes, or potentially even causal mutations, contributing to the phenotype of economically important traits. Such findings could be important for improving the accuracy of breeding value estimation and also to increase our understanding of the mechanisms underlying long-term selection response in artificial breeding program.

A distinct feature of dairy cattle populations is the recent small effective population size that results from a widespread use of artificial insemination. Furthermore, dairy cattle have been subjected to long-term, intensive directional artificial selection and assortative mating scheme for milk production traits in general, and milk yield in particular. This population history has largely influenced the pattern of linkage disequilibrium (LD) in the dairy cattle breeds. For instance, the Bovine Hapmap Consortium [14] reported low, but nonzero, levels of LD at distances of up to $1 \mathrm{Mb}$ in several dairy cattle breeds. As GWAS analyses exploit LD, it is therefore possible to perform powerful genome-wide analyses in dairy cattle with a marker density much lower than that in humans, i.e. using markers positioned every $100 \mathrm{~kb}$ or so [15]. Recent GWAS studies in dairy cattle have primarily focused on the Holstein breed [3-5,16-18], due to its widespread use across the world. Some studies have also been published in other breeds, including one of direct gestation length in Brown Swiss cattle [19].

A major challenge in the statistical analysis of GWAS data is the sensitivity to systematic confounding factors that might lead to false positive associations, and the primary causes of such confounding result from either population stratification or family structure [20]. So far, several different methods to correct for systematic confounding have been proposed [21-23]. However, due to the multiple families and multiple generations in livestock GWAS datasets, the systematic confounding is rather complex. Linear mixed models have been suggested as a way to effectively correct for subpopulation and/or family structure in order to reduce the rate of false positives without too much loss in power [24-27], which makes this method the approach of choice in such situations.

The Brown Swiss cattle is best known for their high milk yield and ability to produce well under challenging conditions in terms of temperature and feed. It is important in dairy production in Western Europe and North America. Since 1996, the Interbull Centre has routinely received data from Brown Swiss bulls from many countries and carried out an international breeding evaluation resulting in comparable estimated breeding values (EBVs) for these bulls across countries. In this study, we make use of the international EBVs of Brown
Swiss bulls from several countries and genotypes from the Illumina Bovine SNP50 Beadchip (Illumina Inc., San Diego, USA) that were collected for use in the national and international genomic prediction effort, to perform a GWAS to identify loci contributing to several for economically important traits in Brown Swiss cattle.

\section{Results}

\section{Description of evaluated phenotypes}

The nine traits selected for this GWAS analysis were milk yield (MY), fat yield (FY), protein yield (PY), lactating cow's ability to recycle after calving (CRC), angularity (ANG), body depth (BDE), stature (STA), milk somatic cell (SCS) and milking speed (MSP). The descriptive statistics of these traits are provided in Table 1. According to the convention for classification of traits at the Interbull Centre, the investigated traits can be classified into five classes: production-, fertility-, conformation-, udder health- and workability traits. In total, genotypes were available for 7038, but here we only included the progeny proven bulls in the GWAS analysis. As the start of the national genetic evaluations, and the measurement time for the traits of daughters differed, the final sample sizes in the GWAS analysis varied between 2061 and 5043 for the traits (Table 1). As the bull's international breeding values were based on both pedigree information and daughter phenotypes, we used a conversion equation to transform EBVs to deregressed-EBVs (DEBVs) to remove the contributions of information from relatives. The DEBVs were then used as the phenotypes in the analysis. The milk production traits had high heritability and the EBVs for these traits were very accurate. Both the reliability and heritability were lowest for the fertility trait.

The pairwise Pearson correlation coefficients for all pairs of traits are given in Table 2. The milk production traits are strongly and positively correlated, but also traits within and between the other categories often had

\begin{tabular}{|c|c|c|c|c|c|c|}
\hline Trait & Trait type & Mean & SD & $\mathrm{n}$ & Mean reliability ${ }^{\mathrm{a}}$ & $h^{2}$ \\
\hline MY & Production & -0.79 & 1.88 & 5043 & 0.809 & 0.360 \\
\hline FY & Production & -0.82 & 1.75 & 5043 & 0.802 & 0.340 \\
\hline PY & Production & -0.95 & 1.70 & 5043 & 0.790 & 0.350 \\
\hline CRC & Fertility & 0.11 & 1.36 & 3807 & 0.643 & 0.039 \\
\hline ANG & Conformation & 0.35 & 4.19 & 2061 & 0.731 & 0.300 \\
\hline $\mathrm{BDE}$ & Conformation & -0.14 & 1.38 & 4402 & 0.741 & 0.372 \\
\hline STA & Conformation & -0.45 & 1.33 & 4610 & 0.824 & 0.428 \\
\hline SCS & Udder health & -0.27 & 1.24 & 4803 & 0.797 & 0.270 \\
\hline MSP & Workability & -0.16 & 1.19 & 4411 & 0.758 & 0.144 \\
\hline
\end{tabular}

a: reliability of EBV values. 
Table 2 Pairwise Pearson phenotypic correlations

\begin{tabular}{lrrrrrrrr}
\hline Trait & MY & FY & PY & CRC & ANG & BDE & STA & SCS \\
\hline FY & 0.891 & & & & & & & \\
PY & 0.893 & 0.921 & & & & & & \\
CRC & -0.315 & -0.295 & -0.269 & & & & & \\
ANG & -0.332 & -0.332 & -0.325 & 0.109 & & & & \\
BDE & 0.415 & 0.391 & 0.369 & -0.115 & -0.336 & & & \\
STA & 0.269 & 0.281 & 0.360 & -0.091 & -0.450 & 0.551 & & \\
SCS & 0.152 & 0.193 & 0.174 & 0.101 & 0.007 & -0.101 & 0.009 & \\
MSP & -0.009 & 0.049 & 0.095 & -0.101 & -0.187 & -0.128 & 0.033 & -0.109 \\
\hline
\end{tabular}

intermediate correlation. The only trait that is only mildly correlated to other traits is milking speed.

\section{Estimation of population stratification using principle component analysis}

To examine the possible population structure in the analyzed population, principal component analysis (PCA) was performed for all 7038 individuals based on the kinship matrix estimated from SNPs. Two sub-groups were identified of 6784 and 254 bulls, respectively (see Additional file 1: Figure S1). The total amount of genetic variance explained by the first two principal components was, however, low (12.01\% and 1.68\%), indicating that this stratification is unlikely to have any strong influence on the outcome of the GWAS analysis. This was also confirmed by further exploratory analyses showing that analyzing the two sub-classes separately produced similar results to those when the whole population was analyzed jointly (results not shown).

\section{Genome-wide association analysis accounting for confounding}

The data was analyzed using a linear mixed model, as implemented in EMMAX [26], and the results corrected using genomic control [21]. The manhattan plots of the obtained $P$ - values are given in Figure 1 (stature) and Additional file 2: Figure S2 (the other 8 traits) (see Additional file 2: Figure S2). A total of 74 genomewide significant SNPs were identified for these nine traits (Table 3). The association signals were distributed across 12 chromosomes, with the strongest signals on BTA25. Some SNPs were significant for multiple traits and the number of uniquely significant SNPs was 50. As shown in the quantile-quantile $(\mathrm{Q}-\mathrm{Q})$ plots for the GWAS analyses (see Additional file 3: Figure S3), the $P$-value inflation was low, but with $\lambda$-values still significantly larger than 1 . However, the $\lambda_{1000}$ values were close to 1.05 , which is generally considered benign [20]. The estimated effect and $P$-values of all the significant SNPs for the analyzed traits are listed in Table S1 (Additional file 4: Table S1).

The peaks for stature, milk yield, fat yield, protein yield, lactating cow's ability to recycle after calving and body depth covered almost the same region on BTA25. The most significant SNP and the number of significant SNPs did, however, vary. Based on the results from the linear mixed model analysis with subsequent genomic control, the number of genome-wide significant SNPs at the peak on BTA25 for stature, milk yield, fat yield, protein yield, lactating cow's ability to recycle after calving and body depth was $26,2,5,3,4$ and 11 , respectively. The 26 associated SNPs with stature covered a $7.65 \mathrm{Mb}$ interval from $32 \mathrm{~kb}$ to $7.95 \mathrm{Mb}$. For body depth, the 11

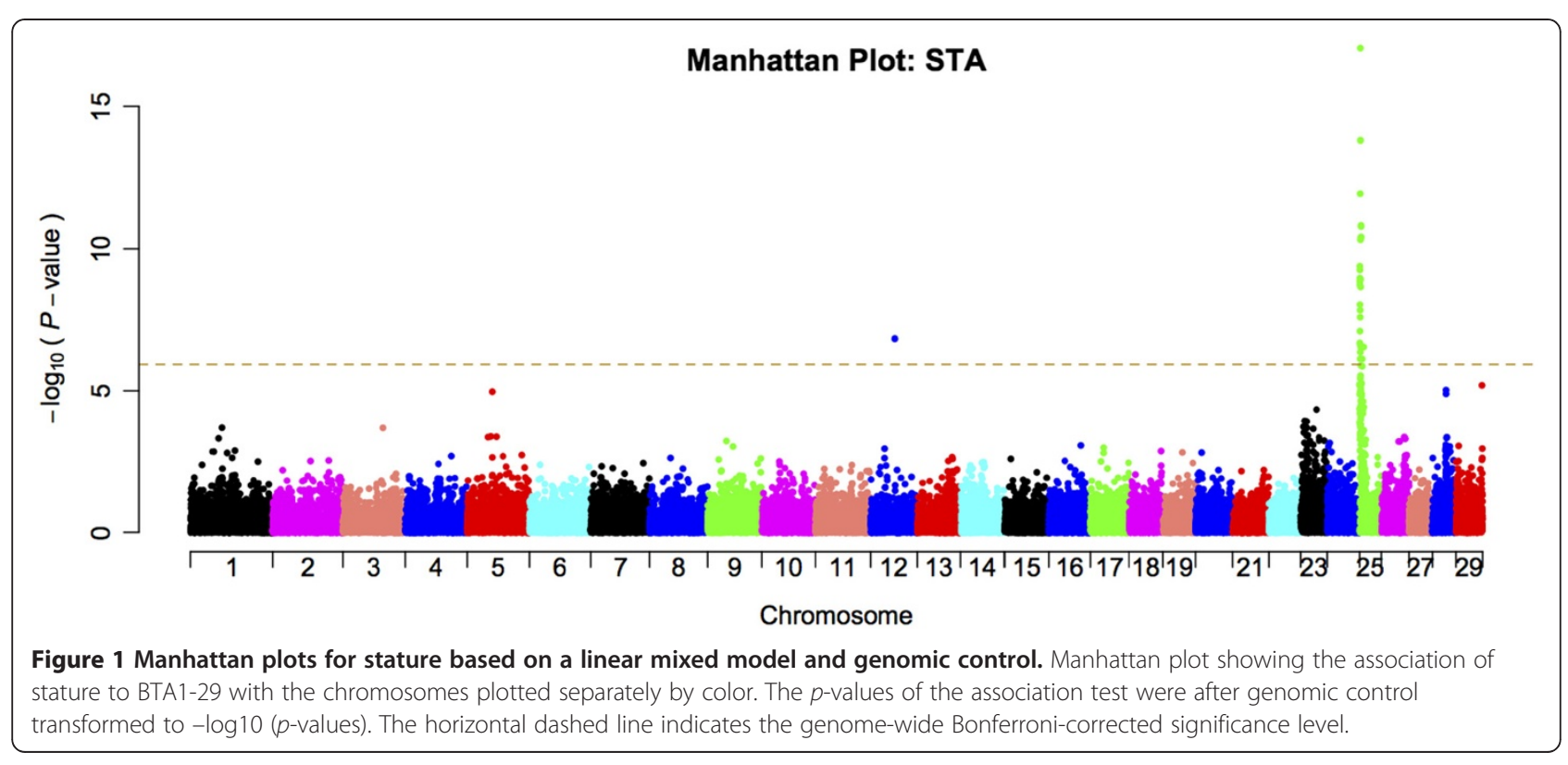


Table 3 Numbers and distribution of genome-wide significant SNPs detected by EMMAX with genomic control

\begin{tabular}{|c|c|c|c|c|c|c|c|c|c|}
\hline \multicolumn{10}{|c|}{ Trait $^{a}$} \\
\hline BTA & MY & FY & PY & CRC & ANG & $\mathrm{BDE}$ & STA & SCS & MSP \\
\hline 1 & & & & & 1 & & & & \\
\hline 5 & 1 & 1 & & & & & & & \\
\hline 6 & & & & & & & & & 2 \\
\hline 8 & & & & & 1 & & & & \\
\hline 11 & & & & & 5 & & & & \\
\hline 12 & & & & & 1 & & 1 & & \\
\hline 17 & & & & & 1 & & & & \\
\hline 20 & 1 & 1 & & & & 1 & & & \\
\hline 24 & 1 & & & & & & & 1 & \\
\hline 25 & 2 & 5 & 3 & 4 & & 12 & 26 & & \\
\hline 28 & 1 & & & & & & & & \\
\hline 29 & & & & & 2 & & & & \\
\hline Total & 6 & 7 & 3 & 4 & 11 & 13 & 27 & 1 & 2 \\
\hline
\end{tabular}

${ }^{a} M Y$ : milk yield, $F Y$ : fat yield, $P Y$ : protein yield, $C R C$ : lactating cow's ability to recycle after calving, ANG: angularity, BDE: body depth, STA: stature, SCS: milk somatic cell count, MSP: milking speed.

genome-wide significant SNPs covered 1.7 Mb from 1.1 to $2.9 \mathrm{Mb}$. A number of genes mapped to the short region closely surrounding the most significant SNPs, including functional candidate genes including insulinlike growth factor binding protein acid labile subunit
(IGFAL), hydroxyacylglutathione hydrolase (HAGH), and heparan sulfate (glucosamine) 3-O-sulfotransferase 6 (HS3ST6) (Figure 2A). A second less significant peak with only one significant SNP was also observed for body depth at $33 \mathrm{Mb}$ on BTA25. In addition, milk yield and fat yield shared one associated SNP at $33.17 \mathrm{Mb}$ on BTA5 and another one at $63.12 \mathrm{Mb}$ on BTA20 (see Additional file 4: Table S1.1, Table S1.2).

A peak consisting of five SNPs with genome-wide significant effects on angularity was detected at the distal region of BTA11. Four of these five SNPs were located between $87.3 \mathrm{Mb}$ and $88.0 \mathrm{Mb}$. The closest gene mapping to this peak is the c-abl oncogene 1 (ABL1) (Figure $2 \mathrm{~B}$ ), but other genes including pyroglutamylated RFamide peptide (QRFP), fibrinogen $C$ domain containing 1 (FIBCD1), laminin gamma 3 (LAMC3) were close to the signal. Other SNPs associated with angularity were also detected on BTA1, 8, 12 and 29.

Several SNPs affecting somatic cell score were located in a peak on BTA24, although only one of these (located at $31.1 \mathrm{Mb}$ ) reached genome wide significance. An interesting candidate microRNA (bta-mir-2380) was located close to the peak at $31.1 \mathrm{Mb}$ (see Additional file 5: Figure S4A).

A signal associated with milking speed was identified on BTA6 and two SNPs, at 90.3 and $90.5 \mathrm{Mb}$, reached the genome-wide significance level. Here, the afamin (AFM or ALB2), alpha-fetoprotein (AFP or FETA_Bovine),

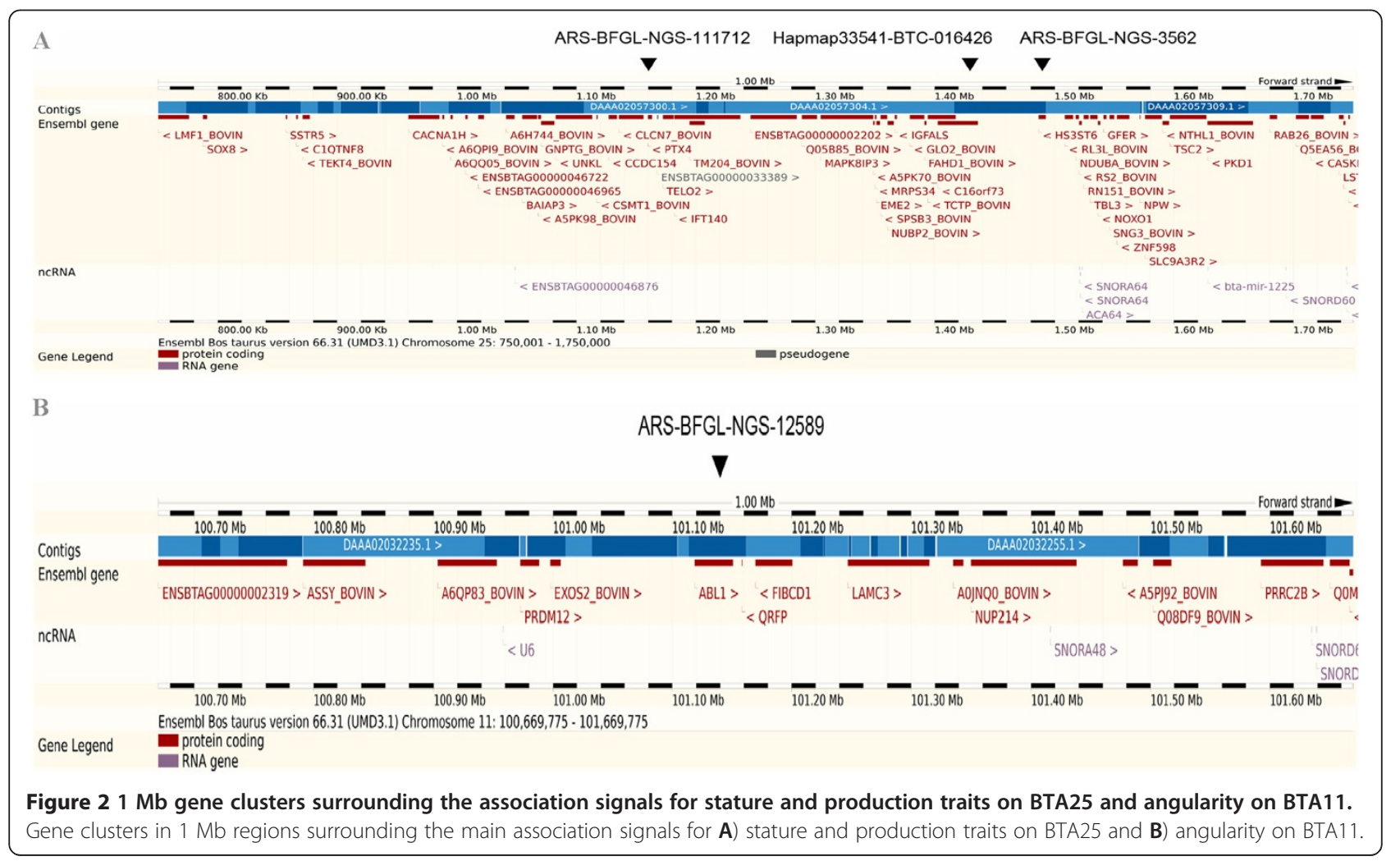


albumin $(A L B)$ as well as the Interleukin-8 (IL8) genes were located in the close vicinity of the peak (see Additional file 5: Figure S4B).

\section{Genome-wide association analysis for production traits conditional on stature}

In order to evaluate the potential pleiotropy of the association peak on BTA25 that affected multiple traits, additional GWAS analyses were performed for the production traits using a linear mixed model, where the stature phenotype was included as a covariate. The results from these analyses show a decrease, although not a complete removal, of the peak surrounding the most significant SNP on BTA25. One SNP for fat yield and protein yield still, however, reached the genome-wide significance indicating that the effect on the production traits is not necessarily a secondary effect of the size of the animal, and a pleiotropic locus with effects on both stature and production might be present (Figure 3; see Additional file 6: Figure S5; see Additional file 7: Figure S6).

\section{Discussion}

\section{Population structure and GWAS}

Here, we made use of the data available from the international genetic evaluation of dairy cattle at Interbull Centre. In this way, we could include most of the Brown Swiss progeny proven bulls from seven countries in a GWAS to obtain a large, powerful sample for detecting genetic variants associated with economically important dairy cattle traits. From a population genetics point of view, this population represents a major part of the paternal genetic material in the contemporary global Brown Swiss population. Given the large population size, this study is expected to provide useful insights to important loci under selection for the main production traits within the Brown Swiss cattle population. To date, no GWAS study on milk production traits and stature in Brown Swiss population has been published, making these results of greater interest as they will allow comparisons with results on studies of other dairy breeds.

Our GWAS study is a population-based study and is then potentially sensitive to population admixture and

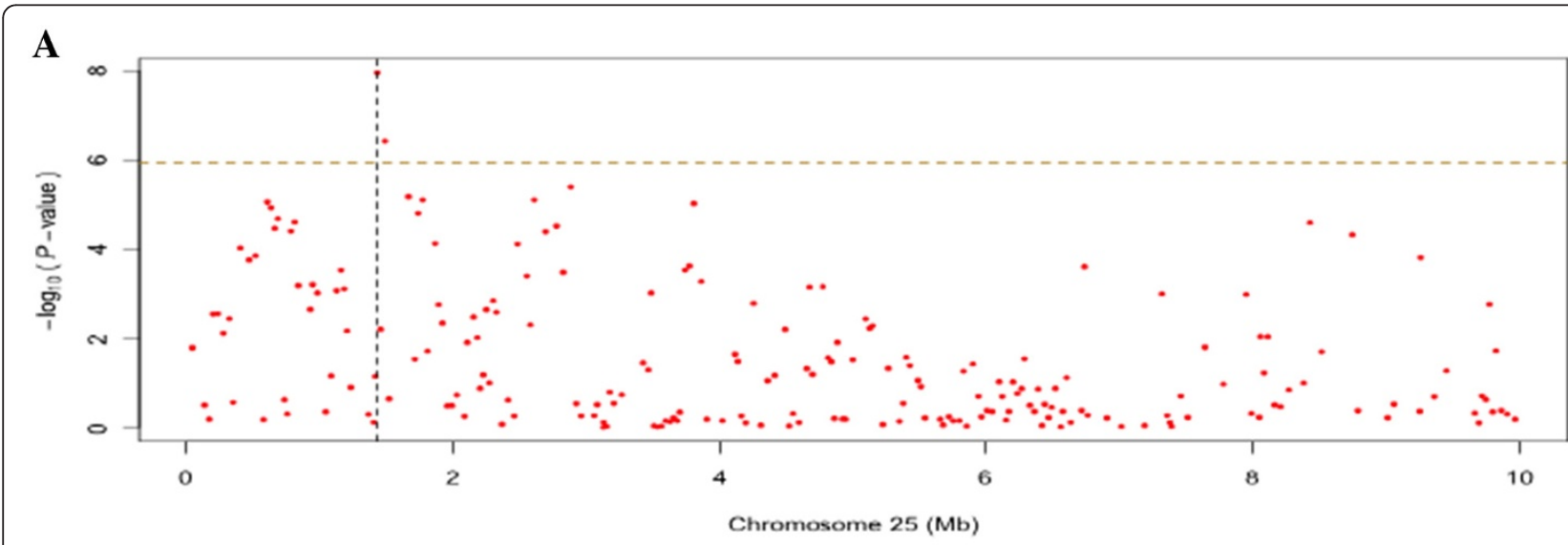

B

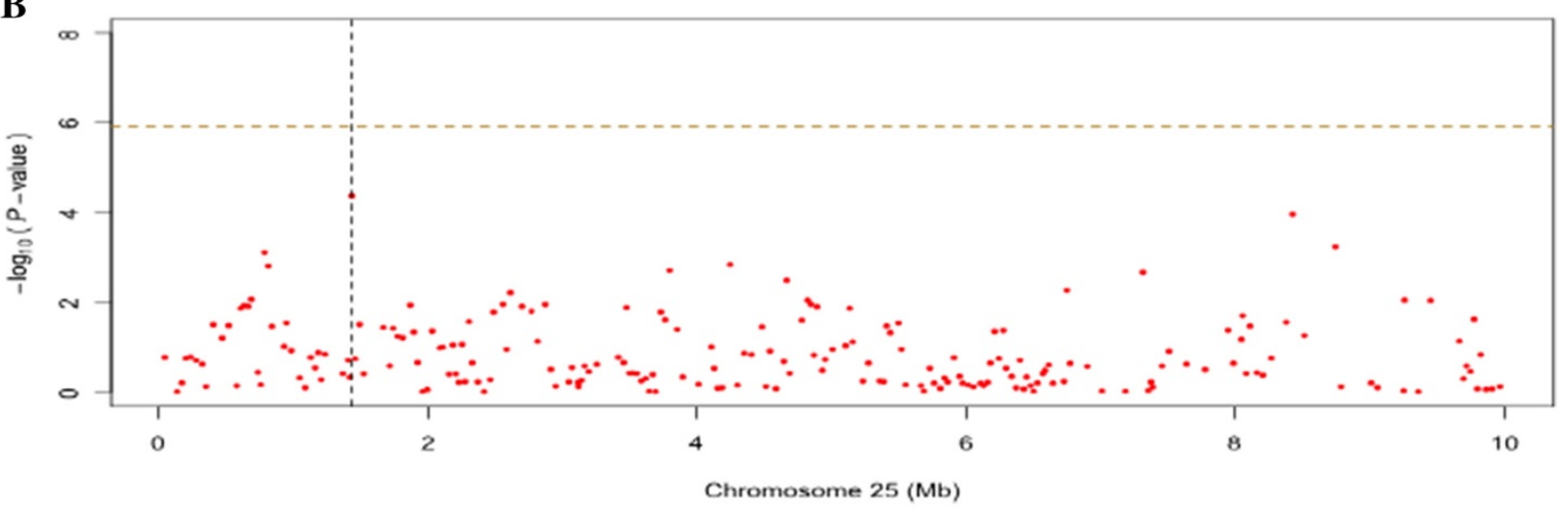

Figure 3 The association of protein yield to BTA25 with and without stature as a covariate. The $p$-values for the association of protein yield to BTA25 was obtained using a linear mixed model and genomic control and then transformed to - $\log 10$ ( $P$-values). The horizontal dashed line indicates the genome-wide significance level (i.e. corrected for testing all markers on BTA1-29). Figure $3 \mathbf{A}$ shows the result of the analysis without and $3 \mathbf{B}$ the analysis with the stature phenotype as a covariate in the linear model. 
familial relatedness caused by recent selection and/or non-random mating. It is well known that these systematic factors could lead to spurious association results, and different approaches correcting for these have been proposed and discussed [21-23]. In this study, we first used PCA analysis to examine whether population structure could be of major concern. The results indicate that the sample of Brown Swiss bulls could be divided into two groups - one large and one small. Compared to other PCA analysis results in structured populations, however, the first and second principal components here explained a much smaller proportion of the total genetic variation. Even though the genomic kinship indicated that the population could be divided into two groups, the overlap with the pedigree structure was small. Most members of the smaller group of bulls originated from Switzerland. We hypothesized that these might be from the original Brown Swiss cattle. However, a PCA analysis of all Brown Swiss cattle from Switzerland (Bapst, personal communication) showed that there is no overlap between the old Brown Swiss cattle and the smaller group in our study. Our interpretation is that the apparent confounding is a false positive result that likely arose in the PCA analysis [28]. As these results suggested that the population structure was not of main concern, we did not exclude the individuals from the smaller group in the final GWAS analysis.

Unlike the normal pattern of confounding factors in human GWAS studies, familial relationship under intensively directional artificial selection is the chief confounding factor in domesticated animal GWAS studies. This can potentially result in genome-wide inflation of the $P$-values in the GWAS and result in false positives in the same way as population stratification. When high familial relatedness exists, but only slight population stratification, linear mixed models are useful for performing powerful association analyses, while at the same time reducing the false positive rate [24-27]. In these analyses, a polygenic random effect term is included to represent the family structure. In our study, the analyses were performed using EMMAX, and the first set of results indicated that an intermediate or small inflation still occurred. There are several potential explanations for this. First, it might be caused by the impact of strong artificial selection influencing a smaller subset of loci, which then will be different from the general impact of subpopulation divergence on the whole genome. Such inflation will differ between different types of traits. Our results from a simple regression analysis of the data are in line with this explanation, as the inflation varied greatly between different types of traits in these analyses (data not shown). Secondly, when a number of loci have strong effects on the traits, the overall inflation of the $P$-values might be affected by some strong signals in the upper tails of the $P$ values. This is something observed here, where for most traits were the strongest deviations from the expected $P$-values under the null-hypothesis is observed in the upper tail of the distribution. Also, the inflation was larger for production traits than for the other traits. As Brown Swiss cattle, in the same way as other dairy cattle, have been most strongly selected for milk production traits, the difference in inflation between the traits could reflect the genomic influence of selection on a limited number of major loci.

\section{Comparison with reported results and pleiotropy for production and body size traits}

As the number of GWAS studies in cattle is still limited, we have made an attempt to overlap our association signals with those of previously reported QTL. Although the complete and exact translation of bovine genetic distances into physical distances is not available, we used the information of the physical map location provided in the cattle QTLdb in animal genome database [29] to do these comparisons.

In our study, the main association was found on BTA25. Most of the significant SNPs were located around 1.1$1.4 \mathrm{Mb}$ and affected stature, milk yield, fat yield, protein yield, lactating cow's ability to recycle after calving and body depth. A second peak was mapped for body depth at around $33 \mathrm{Mb}$. Several earlier studies have reported overlapping QTL for milk- and protein yield on BTA25 at around 32.9- 44.0 Mb (45-69 cM) in Holstein and Finnish Ayrshire [3,29-32]. This peak thus overlapped with our association signal for body depth. No earlier milk production QTL has been reported for our major region. Given the major effect of our locus on stature it is interesting, however, to note that recently reported QTL influencing body weight in an Angus population [33] was located in this region (79 kb-13.3 Mb or 0.6-14 cM). Given that stature, body depth and body weight are all measures of body size, it is possible for them to be sharing underlying pathways and causal variants. Indeed, Cole et al. [18] report that some associated SNPs were shared by the two traits in US Holstein population. The most interesting candidate gene in this region in the NCBI and ENSEMBL databases $[34,35]$ is $I G F A L$. This gene is a serum protein that binds IGFs that regulate growth, development and other physiological process. It interacts with the growth hormones and increases their half-life and their vascular localization [36]. Courtland et al. [37] have earlier reported that sex-specific effects of body- and bone size depended on IGFAL. Furthermore, IGFAL is also known to be associated with growth deficiencies in human [38], which further suggests $I G F A L$ as a major candidate gene for these growth related traits [39]. Based on the GWAS analysis for production traits conditional on the phenotypes of stature, it is reasonable that the alleles at this locus have a pleiotropic 
effect on the growth and milk production traits. Although part of the difference in production could be explained by the basic biological logic that bigger body size leads to higher milk yield, our results indicate that this locus also has direct effects on milk yield, fat yield and protein yield independent of stature.

To date, a total of 16 QTL affecting angularity have been identified [29] on 11 autosomes. A QTL for angularity in a Dutch Holstein population was detected on BTA11 at 9.70-10.66 Mb (19.4 cM) [40], but far away from our signal at 87.3-88.0 Mb.

Schulman et al. [41] reported a QTL affecting somatic cell score at between 28.8 and $30.1 \mathrm{Mb}$ (35.1 cM) on BTA24 in a Finnish Ayrshire cattle population. Recently, another QTL for the same trait was detected between 30.1 and $43.0 \mathrm{Mb}(35.5-48.8 \mathrm{cM})$ on the same chromosome in Danish Holstein cattle [42]. Our association peak at $31.1 \mathrm{Mb}$ for somatic cell score was in the same region as these QTL and also contains a microRNA (bta-mir-2380; Additional file 5: Figure S4A), which is expressed upon viral infection [43].

Milking speed is a workability trait that is very important to dairy producers. Cows that milk out fast require less labour in the milking hall. However, fast-milking cows may be at increased risk for mastitis [44]. The significantly associated SNPs in the peak on BTA6 for milking speed found in this study overlapped with a previously identified QTL in three French dairy cattle breeds [45]. Interestingly, the association signal is located close to IL8 (Additional file 5: Figure S4B), a known member of interleukin family. Further explorations of the relationship between the SNP polymorphism of IL8, milking speed and immune-response could potentially provide new insights to the biological mechanisms underlying this trait.

\section{Conclusions}

Here we report the results from a GWAS analysis of nine production, fertility, conformation, udder health and workability traits using data from the international breeding evaluation program for Brown Swiss cattle. 74 genome-wide significant SNPs were found to be associated with one or multiple traits using an analysis based on a linear mixed model with genomic control. A strong, pleiotropic locus affecting stature, milk yield, fat yield, protein yield, lactating cow's ability to recycle after calving and body depth was found on BTA25. Furthermore, particularly interesting signals were found on BTA11 for angularity, BTA 24 for somatic cell score and BTA6 for milking speed. Most of these signals overlapped with earlier reported QTL for related traits in dairy and beef cattle. Several known functional candidate genes could also be identified in these regions. Our study shows the usefulness of data from international breeding evaluation for identifying genetic variants associated with complex traits and that the overlap between association and QTL signals is apparently large in cattle. Further replication studies, as well as functional dissection of the molecular mechanisms underlying the reported signals, are needed to fully understand the complexity of trait regulation. But this study provides a first important step along this path.

\section{Methods}

\section{Animal population}

Genotypes and national estimated breeding values (EBVs) for a large number of Brown Swiss bulls are routinely delivered to Interbull Centre as part of the international breeding evaluation program for dairy cattle [46]. The national EBVs are then used to calculate an international EBV for each bull that could be used in selection of sires in Brown Swiss cattle breeding programs across the world. At present, the information of 7038 Brown Swiss bulls is available at Interbull Centre. We chose to only use the progeny tested proven bulls in our genome-wide association study, as national genetic evaluation for different traits have different starting points, and different traits were measured at different time in the process of progeny testing. The sample sizes were different for the traits (n = 2061-5043; Table 1).

\section{Adjustment of EBV}

As a bull's breeding value (here international EBVs) includes pedigree information, there is a risk that SNP could be significantly associated with the trait due to the pedigree information rather than phenotype. Thus, deregressed solutions removing the contribution of information from relatives were calculated for each bull. The equation for de-regression [47] is as follows:

$$
D E B V=P A+(E B V-P A) / R E L_{\text {dau }} .
$$

Where $D E B V$ is de-regressed EBV, $P A$ represents parent average, EBV is estimated breeding value, and $R E L_{\text {dau }}$ is reliability from daughters. This conversion analysis was done using the $\mathrm{R}$ package [48]. The bulls used in this study are elite bulls whose EBV has high reliability. The distribution of reliability values has a strong kurtosis and it was therefore deemed that the use of reliability values to weight the DEBV would not improve the results.

\section{Genotype quality control}

Genotype information was initially available for 44,826 SNPs on the Illumina Bovine SNP50K Beadchip. We applied the following quality control of these SNPs before conducting statistical analysis: SNPs were discarded if i) its call rate was less than $90 \%$, ii) if its minor allele frequency (MAF) was less than $2 \%$ or iii) it departed from 
Hardy-Weinberg equilibrium at a threshold of $p<0.01$. Individuals were also excluded from the analysis if they had more than $10 \%$ missing genotypes. There were slight differences in the outcome of the quality control between the traits as the sample of individuals for the traits differed slightly for the reason described above.

\section{Principle component analysis}

To examine whether population stratification was a problem in our data, principle component analysis (PCA) was carried out using the GCTA software [49], which implement the method proposed by Price et al. [28].

\section{Linear mixed model GWAS analyses accounting for confounding}

To analyze this data, where familial confounding existed, a linear mixed model implemented in the program EMMAX [26] was used. The PLINK software [50] was used to edit files before the EMMAX analysis was run. The model implemented is

$$
Y=X \beta+u+\varepsilon
$$

Where $\mathbf{Y}$ denotes the vector of deregressed EBVs (DEBVs), $X$ is the vector of genotypes at the locus being tested, $\beta$ is the additive fixed effect attributed to the locus, and $\varepsilon$ is the vector of residual error with $\varepsilon \sim N$ $\left(0, I \sigma_{e}^{2}\right)$, and $u$ is the vector of the background polygenic effects with $u \sim N\left(0, G \sigma_{u}^{2}\right)$.

The kinship matrix, $G$, describes the genome-wide relatedness between the individuals and is estimated once based on the identity-in-state (IBS) of the genotyped markers. The parameters of the model $\sigma_{u}^{2}$ and $\sigma_{e}^{2}$ are estimated using restricted maximum likelihood (REML) for each SNP. Generalized least squares (GLS) is employed to estimate the effect $\beta$ and an F-test test to test the null hypothesis $H_{O}: \beta=0$.

Significance testing was based on Bonferroni corrected significance thresholds correcting for the number of SNP loci tested. Genomic control [21] was also used in order to correct for the weak inflation that still existed.

\section{Candidate gene identification}

Locations of SNPs and gene clusters were identified based on the Bovine genome NCBI build 6.1 and ENSEMBL $[34,35]$.

\section{Additional files}

Additional file 1: Figure S1. Principal component analysis of the total sample of 7038 bulls. Plot of the first two principal components (PC1 and PC2) of each individual based on SNP information to evaluate the extent of population structure.

Additional file 2: FigureS2. Manhattan plots for eight traits based on a linear mixed model and genomic control. Manhattan plot showing the association of the traits to BTA1-29. The chromosomes are plotted separately by color. The $P$-values of the association were after genomic control transformed to - $\log 10$ ( $P$-values). The horizontal dashed line indicates the genome-wide Bonferroni-corrected significance level. Included traits are MY (milk yield), FY (fat yield), PY (protein yield), CRC (lactating cow's ability to recycle after calving), ANG (angularity), BDE (body depth), SCS (milk somatic cell count) and MSP (milking speed).

Additional file 3: FigureS3. Quantile-quantile $(\mathrm{Q}-\mathrm{Q})$ plots of $P$-values of SNPS from EMMAX for the nine analyzed traits The blue dots represent the association $P$-values. The dark line denotes the expected pattern under the null hypothesis, whereas the red line is the observed pattern. Deviations between the two lines indicate how the test statistics of loci deviate from the null hypothesis. MY: milk yield, FY: fat yield, PY: protein yield, CRC: lactating cow's ability to recycle after calving, ANG: angularity, BDE: body depth, STA: stature, SCS: milk somatic cell count, MSP: milking speed.

Additional file 4: Table S1. Genome-wide significant SNP effects for each of the nine analyzed traits.

Additional file 5: Figure S4. $1 \mathrm{Mb}$ gene clusters surrounding the association signals for somatic cell score on BTA24 and milking speed on BTA6. Gene clusters in $1 \mathrm{Mb}$ regions surrounding the main association signals for A) somatic cell score on BTA24 and B) milking speed on BTA6.

Additional file 6: Figure S5. The association of milk yield to BTA25 with and without stature as a covariate. The $p$-values for the association of milk yield to BTA25 was obtained using a linear mixed model and genomic control and then transformed to - $\log 10$ ( $P$-values). The horizontal dashed line indicates the genome-wide significance level (i.e. corrected for testing all markers on BTA1-29). Additional file 5: Figure S5A shows the result of the analysis without and $5 B$ the analysis with the stature phenotype as a covariate in the linear model.

Additional file 7: Figure S6. The association of fat yield to BTA25 with and without stature as a covariate. The $p$-values for the association of fat yield to BTA25 was obtained using a linear mixed model and genomic control and then transformed to -log10 (P-values). The horizontal dashed line indicates the genome-wide significance level (i.e. corrected for testing all markers on BTA1-29). Additional file 6: Figure S6A shows the result of the analysis without and $6 \mathrm{~B}$ the analysis with the stature phenotype as a covariate in the linear model.

\section{Abbrevations}

GWAS: Genome-wide association study; PCA: Principle component analysis; LD: Linkage disequilibrium; SNP: Single nucleotide polymorphism; Bp: Base pairs; Kb: Kilo base pairs; Mb: Mega base pairs; MAF: Minor allele frequency; cM: CentiMorgan; QTL: Quantitative trait locus; BTAN: Bos taurus chromosome N; EBVs: Estimated breeding values; DEBVs: Deregressed estimated breeding values; MY: Milk yield; FY: Fat yield; PY: Protein yield; CRC: Lactating cow's ability to recycle after calving; ANG: Angularity; BDE: Body depth; STA: Stature; SCS: Milk somatic cell; MSP: Milking speed.

\section{Competing interests}

The authors declare no competing interests.

\section{Authors' contributions}

ÖC and HJ initiated and planned the study. JG implemented the data analysis. JG drafted the manuscript and all authors together wrote the final paper. All authors read and approved the final manuscript.

\section{Acknowledgments}

This study was funded by a Future Research Leader Grant from the Swedish Foundation for Strategic Research and a EURYI Award from ESF to ÖC. Jiazhong Guo acknowledges the China Scholarship Council for the scholarship award for his visiting PhD studies in Swedish University of Agriculture Science. We would like to acknowledge the InterGenomics partners (Arbeitsgemeinschaft der Österreichischen BraunviehZüchter, Austria; Arbeitsgemeinschaft Deutsches Braunvieh, Germany; Associazione nazionale allevatori bovini della razza Bruna, Italy; Brown Swiss Association of the US, USA; Brune Genetique Services, France; Braunvieh Schweiz,

Switzerland; and Zveza rejcev govedi rjave pasme Slovenije, Slovenia) to give 
us permission to use their data in this study. We also thank Xia Shen and other members in the Computational Genetics section for fruitful discussions.

\section{Author details}

'College of Animal Science and Technology, Northwest A\&F University, Yangling, Shaanxi 712100, People's Republic of China. ${ }^{2}$ Department of Clinical Sciences, Division of Computational Genetics, Swedish University of Agricultural Sciences, Uppsala, Sweden. ${ }^{3}$ Department of Animal Breeding and Genetics, Swedish University of Agricultural Sciences, Uppsala, Sweden.

Received: 24 May 2012 Accepted: 22 September 2012

Published: 2 October 2012

\section{References}

1. Hindorff LA, Sethupathy P, Junkins HA, Ramos EM, Mehta JP, Collins FS, Manolio TA: Potential etiologic and functional implications of genomewide associations of genome-wide association loci for human diseases and traits. Proc Natl Acad Sci USA 2008, 106:9362-9367.

2. Visscher PM, Brown MA, McCarthy MI, Yang J: Five years of GWAS discovery. Am J Hum Genet 2012, 90:7-24.

3. Daetwyler HD, Schenkel FS, Sargolzaei M, Robinson JA: A genome scan to detect quantitative trait loci for economically important traits in Holstein cattle using two methods and a dense single nucleotide polymorphism map. J Dairy Sci 2008, 91:3225-3236.

4. Kolbehdari D, Wang Z, Grant JR, Murdoch B, Prasad A, Moore SS: A whole genome scan to map QTL for milk production traits and somatic cell score in Canadian Holstein bulls. J Anim Breed Genet 2009, 126:216-227.

5. Pryce JE, Bolormaa S, Chamberlain AJ, Bowman PJ, Savin K, Goddard ME, Hayes BJ: A validated genome-wide association study in 2 dairy cattle breeds for milk production and fertility traits using variable length haplotypes. J Dairy Sci 2010, 93:3331-3345.

6. Liu W, Liu D, Liu J, Chen S, Qu L, Zheng J, Xu G, Yang N: A genome-wide SNP scan reveals novel loci for egg production and quality traits in white leghorn and brown-egg dwarf layers. PLoS One 2011, 6:1-8.

7. Gregersen VR, Conley LN, Sorensen KK, Guldbrandtsen B, Velander IH, Bendixen C: Genome-wide association scan and phased haplotype construction for quantitative traits loci affecting boar taint in three pig breeds. BMC Genomics 2012, 13:22.

8. Zhao K, Tung CW, Eizenga GC, Wright MH, Ali ML, Price AH, Norton GJ, Islam MR, Reynolds A, Mezey J, McClung AM, Bustamante CD, McCouch SR: Genome-wide association mapping reveals a rich genetic architecture of complex traits in Oryza sativa. Nature 2011, 467:1-10.

9. Atwell A, Huang YS, Vilhalmsson BJ, Willems G, Horton MLY, Meng D, Platt A, Tarone AM, Hu TT JR, Muliyati NW ZX, Amer MA, Baxter I, Brachi B, Chory J, Dean C, Debieu M, Meaux JD, Ecker JR, Faure N, Knikern JM, Jones JDG, Michael T, Nemri A, Roux F, Salt ED, Tang C, Todesco M, Traw MB, Weigel D, Marjoram P, Borevitz JO, Bergelson J, Nordborg M: Genome-wide association study of 107 phenotypes in Arabidopsis thaliana inbred lines. Nature 2010, 465:627-631.

10. Georges M, Nielsen D, Mackinnon M, Mishra A, Okimoto R, Pasqino AT, Sargeant LS, Sorensen A, Steele MR, Zhao X, Womack JE, Hoeschele I: Mapping quantitative traits loci controlling milk production traits in dairy cattle by exploiting progeny testing. Genetics 1995, 139:907-920.

11. Andersson L, Georges M: Domestic-animal genomics: deciphering the genetics of complex traits. Nat Rev Genet 2004, 5:202-212.

12. Goddard ME, Hayes BJ: Mapping genes for complex traits in domestic animals and their use in breeding programmes. Nat Rev Genet 2009, 10:381-391

13. Hirschhorn JN, Daly MJ: Genome-wide association studies for common diseases and complex traits. Nat Rev Genet 2005, 6:95-109.

14. The Bovine Hapmap Consortium: Genome-wide survey of SNP variation uncovers the genetic structure of cattle breeds. Science 2009, 24:528-532.

15. de Roos APW, Hayes BJ, Spelman R, Goddard ME: Linkage disequilibrium and persistence of phase in Holstein Friesian, jersey and angus cattle. Genetics 2008, 179:1503-1512.

16. Bolormaa S, Pryce JE, Hayes BJ, Goddard ME: Multivariate analysis of a genome-wide association study in dairy cattle. J Dairy Sci 2010, 93:3818-3833.

17. Jiang L, Liu JF, Sun DX, Ma PP, Ding XD, Yu Y, Zhang Q: Genome-wide association studies for milk production traits in Chinese Holstein population. PLoS One 2010, 5:e13661.
18. Cole JB, Wiggans GR, Ma L, Sonstegard TS, Thomas JU, Crooker BA, Tassell CPV, Yang J, Wang S, Matukumalli LK, Da Y: Genome-wide association analysis of thirty one production, health, reproduction and body conformation traits in contemporary U.S. Holstein Cow. BMC Genomics 2011, 12:408.

19. Maltecca C, Gray KA, Weigel KA, Cassady JP, Ashwell MA: A genome-wide association study of direct gestation length in US Holstein and Italian Brown populations. Anim Genet 2011, 42:585-591.

20. Price AL, Zaitlen NA, Reich D, Patterson NJ: New approaches to population stratification in genome-wide association studies. Nat Rev Genet 2010, 11:459-463.

21. Devlin B, Roeder K: Genomic control for association studies. Biometrics 1999, 55:9997-1004

22. Pritchard JK, Stephens M, Rosenberg N, Donnelly P: Association mapping in structured populations. Am J Hum Genet 2000, 67:170-181.

23. Price AL, Patterson NJ, Plenge RM, Weinblatt WE, Shadick N, Reich D: principal component analysis corrects for stratification in genome-wide association studies. Nat Genet 2006, 38:904-909.

24. Yu J, Pressoir G, Briggs W, Vroh Bl, Yamasaki M, Doebley JF, McMullen MD, Faut BS, Nielsen DM, Holland JB, Kresovich S, Buckler ES: A unified mixedmodel method for association mapping that accounts for multiple levels of relatedness. Nat Genet 2006, 38:203-208.

25. Kang HM, Zaitlen NA, Wade CM, Kirby A, Heckerman D, Daly MJ, Eskin E: Efficient control for population structure in model organism association mapping. Genetics 2008, 178:1709-1723.

26. Kang HM, Sul JH, Service SK, Zaitlen NA, Kong SY, Freimer NB, Sabatti C, Eskin E: Variance component model to account for sample structure in genome-wide association studies. Nat Genet 2010, 42:348-354.

27. Zhang Z, Ersoz E, Lai CQ, Todhunter RJ, Tiwari HK, Gore MA, Bradbury PJ, Yu J, Arnett DK, Ordovas JM, Buckler ES: Mixed linear model approach adapted for genome-wide association studies. Nat Genet 2010, 42:355-360.

28. Patterson NJ, Price AL, Reich D: Population structure and Eigenanalysis. PLoS Genet 2006, 2:2074-2093.

29. Hu ZL, Park CA, Fritz E, Reecy JM: QTLdb: A comprehensive database tool building bridges between genotypes and phenotypes. Germany: Proc 9th Worldd Cong Genet Appl Livest Prod Leipzig; 2010.

30. Viitala SM, Schulman NF, Koning DJ, Elo K, Kinos R, Virta A, Virta J, Tanila AM, Vilkki JH: Quantitative trait loci affecting milk production traits in Finnish ayrshire dairy cattle. J Dairy Sci 2003, 86:1828-1836.

31. Schrooten C, Bink MCAM, Bovenhuis $\mathrm{H}$ : Whole genome scan to detect chromosomal regions affecting multiple traits in dairy cattle. J Dairy Sci 2004, 87:3550-3560.

32. Harder B, Bennewitz J, Reinsch N, Thaller G, Thomsen H, Kuhn C, Schwerin M, Erhardt G, Förster M, Reinhardt F, Kalm E: Mapping of quantitative trait loci for lactation persistency traits in German Holstein dairy cattle. J Anim Breed Genet 2006, 123:89-96.

33. McClure MC, Morsci NS, Schnabel RD, Kim JW, Yao P, Rolf MM, McKay SD, Gregg SJ, Chapple RH, Northcutt SL, Taylor JF: A genome scan for quantitative trait loci influencing carcass, post-natal growth and reproductive traits in commercial angus cattle. Anim Genet 2010, 41:597-607.

34. National Center for Biotechnology Information (NCBI): Bovine genome resources. [http://www.ncbi.n/m.nih.gov/mapview/].

35. ENSEMBL genome browser. [http://www.ensembl.org/index.html].

36. Leong SR, Baxter RC, Camerato T, Dai J, Wood WI: Structure and functional expression of the acid-labile subunit of the insulin-like growth factor binding protein complex. Mol Endocrinol 1992, 6:870-876.

37. Courtland HW, DeMambro V, Matnard J, Sun H, Elis S, Rosen C, Yakar S: Sexspecific regulation of body size and bone slenderness by the acid labil subunit. J Bone Miner Res 2010, 25:2059-2068.

38. David A, Rose SJ, Miraki-Mound F, Metherell LA, Savange MO, Clark AJ, Camacho-Huber C: Acid-labile subunit deficiency and growth failure: description of two novel cases. Horm Res Paediatr 2010, 73:328-334.

39. Domene HM, Bengolea SV, Jasper HG, Boisclair YR: Acid-labile subunit deficiency: phenotypic similarities and differences between human and mouse. J Endocrinol Invest 2005, 28(5 Suppl):43-46.

40. Schrooten C, Bovenhuis H, Coppieters W, Van Arendonk JAM: Whole genome scan to detect quantitative trait loci for conformation and functional traits in dairy cattle. J Dairy Sci 2000, 83:795-806. 
41. Schulman NF, Viitala SM, Koning DJ, Virta J, Tanila AM, Vilkki JH: Quantitative trait loci for health traits in Finnish ayrshire cattle. J Dairy Sci 2004, 87:443-449.

42. Lund MS, Guldbrandtsen B, Buitenhuis AJ, Thomsen B, Bendixen C Detection of quantitative trait loci in Danish Holstein cattle affecting clinical mastitis, somatic cell score, udder conformation traits and assessment of associated effects on milk yield. J Dairy Sci 2008, 91:4028-4036.

43. Glazov EA, Kongsuwan K, Asssavalapsakui W, Horwood PF, Mitter N, Mahony TJ: Repertoire of bovine miRNA and miRNA-like small regulatory RNAs expressed upon viral infection. PLoS One 2009, 4:e6349.

44. Zwald NR, Weigel KA, Chang YM, Welper RD, Clay JS: Genetic evaluation of dairy sires for milking duration using electronically recorded milking times of their daughters. J Dairy Sci 2005, 88:1192-1198.

45. Boichard D, Grohs C, Bourgeois F, Cerqueira F, Faugeras R, Neau A, Rupp R, Amigues $Y$, Boscher MY, Leveziel H: Detection of genes influencing economic traits in three French dairy cattle breeds. Genet Sel Evol 2003, 35:77-101.

46. Jorjani H, Jakobsen J, Nilforooshan MA, Hjerpe E, Zumbach B, Palucci V, Dürr J: Genomic evaluation of BSW populations, InterGenomics: Results and Deliverables. Interbull Bulletin 2012, 43:5-8.

47. VanRaden PM, Wiggans GR: Derivation, calculation, and use of national animal model information. J Dairy Sci 1991, 74:2737-2746.

48. R development Core Team: R: A language and environment for statistical computing. Vienna, Austria: R Foundation for Statistical Computing; 2008 [http://www.r-project.org/. ISBN 3-900051-07-0.

49. Yang J, Lee SH, Goddard ME, Visscher PM: GCTA: a tool for genome-wide complex trait analysis. Am J Hum Genet 2011, 88:76-82.

50. Purcell S, Neale B, Todd-Brown K, Thomas L, Ferreira M, Bender D, Maller J, Sklar P, Bakker PIW, Daly MJ, Sham PC: PLINK: a tool set for whole-genome association and population-based linkage analyses. Am J Hum Genet 2007, 81:559-575.

doi:10.1186/1471-2156-13-82

Cite this article as: Guo et al:: A genome-wide association study using international breeding-evaluation data identifies major loci affecting production traits and stature in the Brown Swiss cattle breed. BMC Genetics 2012 13:82.

\section{Submit your next manuscript to BioMed Central and take full advantage of:}

- Convenient online submission

- Thorough peer review

- No space constraints or color figure charges

- Immediate publication on acceptance

- Inclusion in PubMed, CAS, Scopus and Google Scholar

- Research which is freely available for redistribution 